\title{
Increasing Literacy Through Specific Tasks Design
}

\author{
Wang Hui-ya (Anny) \\ Minghsin University of Science and Technology, Hsinchu city, Taiwan
}

\begin{abstract}
This study focuses on thirty-five Low-level/achieving students on General Education English which meets for two hours per week, eight weeks for two consecutive semesters (totaling thirty-two hours) in the University of Technology in Taiwan. Its chief aims four-fold: First, to promote the students' learning motivation; second, to increase the students' learning interests; third, to raise their English abilities by reading theme-based/oriented topics; and, fourth, instruct them by giving guidelines to make Power-Point presentations in class. A prior or pilot survey was conducted to provide empirical opportunities to collect and explore the participants' views, comments, and opinions in relation to the selected research questions on this topic. The results also indicate that students can speak different/various length of words, utilize appropriate phrase to express their ideas or goals, and to speak in various/different paces, etc. Teachers couldn't assess the students only by their test results due to the different learning styles adopted by individual students; however, through this survey, students can be better assisted through the identification of their individual styles or habits, their individual styles or habits of learning. As regards relevant knowledge about their students' learning styles, teachers may consider whether and how to adjust their methods of teaching in order to better motivate them to learn English more effectively and efficiently.
\end{abstract}

Keywords: task-based, learner's motivation, learning styles

\section{Introduction}

Students in the University of Technology, in general, perform poorly or unsatisfactorily on their English subjects and many colleges and universities have set their minimum English graduation threshold or crucial level for them to meet or reach. Thus, in order to help the low-level students to develop and adopt effective learning strategies that suits their learning styles so as to achieve better English. The project focuses on 35 non-English major EFL students specifically on how to increase their vocabulary and basic grammar knowledge, on which the teacher read the topics and gave the participants an opportunity to conduct a Power-Point presentation as a strategy to practice using that vocabulary grammar that had been learned. The results were positively reflected by the noticeable difference in terms of progress between the post-test and pre-test.

\section{Review of Literature}

Since the students know best if their enthusiasm for learning increases due to the instruction they received, the favorable or desirable outcome of the research/evaluation projects for English teaching effectiveness could have been achieved or produced. However, the evaluation itself is never a simple task. The research on how

Wang Hui-ya (Anny), M.A. in TESOL and Early Childhood Education, Lecturer, Language Teaching Center, Minghsin University of Science and Technology. 
relevant evaluation data can be collected and measured makes it harder to conduct it, given the growing importance on teaching effectiveness which is determined by relatively diverse and highly complex nature of the enthusiasm and efficiency of both the learners and teachers.

In order to help students learn effectively, the instructors should first understand students' learning styles and offer students opportunities to learn in their preferred ways. Learning styles have been widely defined as the preferred way in which an individual carries out a task or tries to solve the problem (Cassidy, 2004; Oxford, 2003).

Reid's (1995) divided learning styles into three types: visual/auditory, tactile/kinesthetic, and individual/group. Other well-known educators like Felder and Soloman (2000) who have identified several different types of learning styles categorized into four types: active/reflective, sensing/intuitive, visual/verbal, and sequential/global. Considering that most Asian learners are inclined visual learners, I adopted the use of Power-Point presentations in this research.

The texts used in guided reading usually present some challenges, which, however, could be overcome when supported by the direct classroom interactions conducted between the teacher and students. In the classes, the students are provided with English books on tourism with a variety of major topics to choose from.

Intrinsic motivation, which refers to "desire to do something based on a combination of interest, enjoyment, and personal challenge” (Oxford, 2011, p. 72), often, attracted the attention from many researchers. As Shimokawara (2011) argues, the EFL context often lacks learners' frequent contact with their target language in daily life and sufficient quality of target. It is probably difficult to intrinsically motivate the learners in this environment.

Power-Point presentations help students to learn the focused vocabulary and basic grammar in a meaningful context. The inclusion of greater amounts of de-contextualized vocabulary instruction, such as word lists, should be supplemented by gradually increasing toward more context-based vocabulary learning, such as extensive processes may also help to retain long term memory.

\section{Research Design}

This study was conducted by the combination of a qualitative approach case study and an interpretative approach. Guided reading tasks of those selected English topics chosen by them were conducted for a total of thirty-two hours of the semester through power-point presentation. The pre-test and the post-test were administered on the first and the last week of class. A survey was to be given to analyze learners' motivation, materials used, and feedback and comments on their teachers.

The expected results are aimed to increase vocabulary abilities and enhance their grammatical knowledge and usage, and to generate students' motivations, and excite or stimulate their interests and then maintain and sustain them. In the future, there will be more in-depth discussions on the topics, and internalization concepts will be blended into the topic, adding to the grammar teaching activities which suit the students' needs in order to strengthen the self-efficacy and practices.

\section{Participants}

This study focuses on thirty-five Low level non-English major students on General Education English for two hours per week, sixteen weeks for two semesters (totaling thirty-two hours) in the University of Technology in Taiwan. This study examines how motivations, learning styles and strategies, and evaluation 
could have influenced their English vocabulary and basic grammar learning.

\section{Data Collection}

The participants were asked to fill out the questionnaire and the results were compared with the information gained respectively from the observations, Power-Point presentations and pre-test and post-test.

The information gathered was then subject to an inductive analysis, in which the themes and categories emerge from the data rather than being imposed on them prior to collection. An emergent and interactive approach was therefore used by dividing the data collected into analysis stages, in an attempt to go deeper into participants' experiences.

\section{Results}

The themes or featured topics included some important or popular Taiwanese scenic spots and snack foods, that would need many students to get together to visit those places of interests and try to taste them. Those lowest achiever students who have lagged behind in the class were mostly afraid of speaking English. However, they still could gain the presentation skills taught through actually using some relevant vocabularies and grammatical usages or structures by searching the words and expressions on the internet, looking up in the dictionaries and the related books on tourism in the library, gathering the information on the assigned field trips by visiting the scenic spots in order to prepare for their respective Power-Point presentations. Those graphics collected pictures taken during the preparation stage have become one slide stories after another with logic and meaningful phrases and expressions to help them promote oral practice and hone their presentation skills.

From my observation, the major abilities those Low level class students have gained are:

(1) Speak different length of words;

(2) Utilize appropriate phrase to express their goals;

(3) Speak in different places;

(4) Speak natural phrases;

(5) According to the situation, the participants and the communication goals are to accomplish the functions;

(6) In daily conversation, utilize appropriate structure, implicature, pragmatic conventions, and social linguistic features;

(7) Use expressions, gestures, body language, and other clues to express feelings.

During the whole processes such topics were adopted that could generate the intrinsic motivations, through real-life language and meaningful situational teaching activities. The class was divided into groups by individual interest for making their respective presentations on tourism topics about various sightseeing spots or highlights in Taiwan. Since most of the students have already had their background knowledge and life experiences about the contents in Chinese, they could gain their skills by discussing the presentation procedures with the teacher and their peers over and over again, through the preparatory processes or stage of data collection and analysis, discussions, revisions, and further revisions before the actual presentation day in front of the class. This procedure would also encourage the goal of self-learning or self-study since they may choose their topics out of their individual interest or liking; gather the information on their own, and finally make their oral presentations.

However, due to the restriction of classroom time and space, not all of the students could pass through and experience all these processes. Some students complained about it not being fair to get their work done by such 
processes arrangements, since their work might be done only by a few hard working team members. Also, because the regular Wednesdays are reserved for holding discussions some explained they could not join the discussions; instead, a few of the discussions were done through email exchanges, thereby making some students to miss the chance of practicing their pronunciation skills to speak more fluently, naturally, and effectively.

It is expected that in the future researches, the restraining factor of time and space can be addressed and improved in order for the participating students to learn more fairly and effectively through better labor division and duty sharing.

\section{Discussion}

\section{Motivation}

From the test results, it is my observation that the participants have been intrinsically and/or extrinsically motivated to learn English as their second language. According to self-determination theory, there are two types of motivation: one based on intrinsic interest in the activity and the other based on rewards which is extrinsic to the activity itself. These types of motivation lie at some spots or various points along the continuum of students' self-determination. Intrinsic motivation generally refers to motivation to engage in an activity because that activity is enjoyable and satisfying to do. In contrast to intrinsic motivated behaviors, extrinsically motivated behaviors are those actions carried out to achieve some instrumental end, such as earning a reward or avoiding a punishment. If a teacher could find out the motivations for each student to learn a language, such learning could become much more interesting.

\section{Tasks to Increase Literacy}

According to Appendix D and Appendix E, it was discovered that the students learn better when the teacher is more friendly, shares his/her first-hand life experience in English-speaking countries especially in the U.S., teaches in a much more patient attitude than peers to explain everything in details, uses relatively vivid styles of teaching, being more fun and is more open-minded—all these factors will encourage students to learn more effectively and be self-motivated, in order to achieve greater effectiveness and more desired results.

Due to the graduation threshold implemented in English testing requires all the students to take the English proficiency tests. Some students suggested the teacher can teach English for certificate earning purpose, introduce and add more vocabularies, grammatical usage and structures, reading skills, and enhancement materials to help students learn with a test-preparing focus, to strengthen practicing such key tests as the GEPT or TOEIC exams. Teacher evaluation can not only be focused on the students' test results, but also on their interests and needs. Lower level students need to get more guidance on the basics, such as pronunciation drills and grammatical knowledge and practice on structures and usage. The teacher should play a role as a facilitator to help student learn more effectively, make the learning processes more enjoyable and easier to learn, and to improve and enhance their motivation, so as to achieve their goals.

\section{Conclusion}

In addition to the language learning environment, teachers could encourage students to generally strengthen their motivation to learn the English language this could be achieved by creating a pleasant and highly positive atmosphere, developing good interactions and relationships among the students, making the classes interesting, and encouraging them to develop and formulate their own learning strategies more proactive 
and effective; then the teaching of the English language would become more effective and productive.

Understanding one's learning styles to facilitate learning. Employ strategies that are suitable to one's learning styles could make one's learning results more positive, favorable and satisfactory. Project work focuses on content-based learning rather than on specific language skill-building or honing targets. Real-life world topics of interests that are close to students' daily life and major study can be made central or priority to the topics for teaching and learning. Those tasks lead to the integration and actual use of the four skills and processing of information drawn from their real-life experiences to design the learning tasks or projects. The value of the project, however, lies not just in the final product but in the processes of working towards the end. Besides, due to the combination of different evaluation systems, teachers should not impose any single discipline on students who could be made to have experienced a different system of multiple evaluations to prevent students from any disappointments and frustrations. These students should be evaluated based on a different scale or standard or system until they could have been well adjusted to them. Teachers should keep close contacts with such students and/or their parents to afford a good student-teacher communication and collaboration in-between that could dramatically facilitate the transition processes of these students into new environments and transformation into higher achiever students at a higher level of English proficiency.

Due to the limited time and space, the boundary of this study just focused on the thirty-five Taiwanese students in the University of Technology General Education English class setting. The data collection was limited to the survey questionnaires, Power-Point presentations, and pre-test and post-test, since the lack of the previous educational documents such as students' portfolio, transcripts, observations in the classrooms, quantitative data, and interviews with the previous teachers, etc.

There is currently a belief that language, identity, and culture are inextricably related and that language loss has a great influence on children's or adults' changing identities. The two apparently similar language learners in this study, who differed significantly in their fundamental approaches to problem-solving, underscores the insights provided by microanalysis of learner behavior on varied tasks. Future case studies should be explored to facilitate researchers to verify critical assumptions about the strategies and effectiveness in second language acquiring and learning in cross-cultural educational systems and environments.

\section{References}

Brown, H. D. (2000). Principles of language learning and teaching (4th ed.). White Plains, NY: Pearson Education.

Brown, H. D. (2008). Teaching by principles: An interactive approach to language pedagogy (2nd ed.). White Plains, NY: Pearson Education.

Candlin, C. N., \& Hall, D. R. (2011). Teaching and researching speaking. Harlow: Pearson Education Limited.

Cassidy, S. (2004). Learning styles: An overview of theories, models, and measures. Educational Psychology, 24(4), $419-444$.

Felder, R. M., \& Soloman, B. A. (2000). Index of learning styles. Retrieved from http://www.ncsu.edu/felder-public/ILSpage.Htm Nunan, D. (1988). The learner-centered curriculum. Cambridge: Cambridge University Press.

Nunan, D. (1989). Designing tasks for the communicative classroom. Cambridge: Cambridge University Press.

Oxford, R. L. (2003). Learning styles and strategies: Concepts and relationships. IRAL, 41, 271-278.

Oxford, R. L. (2011). Teaching and researching language learning strategies. Harlow: Pearson Education Limited.

Reid, J. M. (1995). Learning styles in the ESL/EFL classroom. Boston, MA: Heinle and Heinle.

Richards, J. C., \& Rodgers, T. S. (1986). Approaches and methods in language teaching. Cambridge: Cambridge University Press.

Shimokawara, H. (2011). Foreign language learning motivation of Japanese high school students: A study from the perspective of self-determination theory (Unpublished master thesis, Waseda University). 


\section{Appendix A}

Survey Results:

\begin{tabular}{llll}
\hline & Agree & Fair & Disagree \\
\hline 1. After this task, I prefer to learn English & $15(43 \%)$ & $20(57 \%)$ & 0 \\
2. I feel my English abilities has improved after this task & $7(20 \%)$ & $18(51 \%)$ & 0 \\
3. I feel less pressured during this task & $22(63 \%)$ & $13(37 \%)$ & 0 \\
4. I am more adapted to the classroom textbook after this task & $20(56 \%)$ & $19(54 \%)$ & 0 \\
5. I study hard during this task & $19(54 \%)$ & $16(46 \%)$ & 0 \\
6. This task is helpful in learning English & $25(71 \%)$ & $10(29 \%)$ & 0 \\
7. I think whether I like this task or not depending on the teacher & $33(94 \%)$ & $2(6 \%)$ & 0 \\
8. I feel whether I like to take this task depending on the materials & $19(54 \%)$ & $16(46 \%)$ & 0 \\
\hline
\end{tabular}

Textbook-wise:

- Not bad

- I am used to it, not too hard, it's more clear

- Buy cheaper ones, students are poor!

- Not bad!

- Not bad!

- Not bad!

- Alright!

- Some grammar is more difficult, I am more interested in learning a different way

- $\mathrm{Ok}$

- Easy to understand

- The content is very helpful

- none

- none

- so, so

Teaching-wise:

- The teacher is good, and easy to get along with

- The teacher is very nice, I feel no pressure

- Could be better

- Very good, hope she continues to teach

- Very good, I like it very much! I like to take her class

- Very good!

- Interesting! I hope the schedule could be later; it's too early in the morning

- Earnest!

- None

- Can be more active, sometimes boring

Are you willing to take this project next time?

- Yes 25

- $\quad$ No 7

- Need considerations 1 


\section{Appendix B}

Table 1

2013 GEPT Pre-test and Post-test in My Class

\begin{tabular}{lllll}
\hline & Listening & Reading & Total & Students \\
\hline Pre-test & 37.1 & 36.3 & 73.4 & thirty-five \\
Post-test & 47.3 & 47.4 & 94.7 & thirty-five \\
\hline
\end{tabular}

Table 2

2013 Pre-test and Post-test in College of Service Industries of The Language Teaching Center of Minghsin University of Science and Technology

\begin{tabular}{lllll}
\hline & Listening & Reading & Total & Students \\
\hline Pre-test & 61.93 & 63.98 & 125.22 & 490 \\
Post-test & 64.87 & 68.22 & 133.09 & 490 \\
\hline
\end{tabular}

\section{Appendix C}

Curriculum:

1st Semester:

Unit 1: Geography

Unit 2: Population

Unit 3: Languages

Unit 4: Traditional arts

Unit 5: Food culture

Unit 6: Popular foods and drinks

Unit 7: Night markets

Unit 8: Local Festival

\author{
2nd Semester: \\ Unit 1: Taipei-Getting around and museums \\ Unit 2: Taipei-attractions \\ Unit 3: Hinchu and Taichung \\ Unit 4: Taichung-Attractions \\ Unit 5: Tainan-Attractions \\ Unit 6: Kaohsiung-Attractions \\ Unit 7: Kenting \\ Unit 8: The East Coast-Hualien and Taitung
}

\section{Appendix D: A Survey on Level of Course Satisfaction in Freshman English}

Miscellaneous comments or recommendations for this course:

Like the easy-going, pressure-free teaching style; need developing or acquiring a basic literacy or vocabulary; could not understand the text;...nothing special to say, thank you teacher anyway; a great teacher to learn from; made a little progress in English learning because the teacher explains very clearly, without putting too much pressure on us; thank you for teaching us enthusiastically and patiently; the teacher sometimes shares her life experience in the United States, which is very interesting, and helps catch and hold our attention in class; feel very easy to learn English more freely in a humorous gentle style, with a lot of fun; her open-mindedness does not place extra burden on us; we all like to learn English easily, happily in a lively and vivid way for a good education by making persistent efforts; use of film dialogues is a very exciting start to increase our interest in further reading about the story content, due to the teacher's detailed explanation and good description, enabling me to quickly understand English.

Thank you for earnest teaching in an easy-going, lively, casual teaching style in which the teacher always tries to interact with the students, though some does not pay attention as nowadays it's not the norm for the students to interact well with one another in class; teacher uses other ways to attract attention, while taking the class seriously, sharing many life experiences overseas, assigning extra reading comprehension exercises, grammar exercises, and encouraging or initiating group discussions; I think the teacher should be more active and have a sense of humor; we made great progress, with a lot of self-improvement, cheers! Unlike all the constraints in junior or senior high schools where all the grades given to students were only determined by test results, here the English classes are more interesting, but the textbook is boring; we need more interaction, more open-minded in offering teaching materials, not just teach according to the textbooks; however, my English ability has improved a lot because 
the teacher is great; I can keep up with the progress, unlike my previous study laden with pressure, thank you for your teaching, which helps generate more interest through film viewing in conjunction with textbooks, without feeling bored anymore, so I think it would help us a lot in taking English proficiency tests to get certificates; Teacher's translation is easy to understand, with more focused on important phrases; we hope the teacher should come to class earlier, and give more movie-watching to help improve our English listening skills, and finish the class with a wrap-up earlier to sometimes allow some students to catch their service-learning class; we hope the teaching can be made more interesting, active and vivid, so as to help me improve my English as I am doing my best to better it, without feeling bored and losing interest. I hope the teacher can provide us with more English resources, to help me better understand the meaning of many sentences that are difficult to me, and I will do my best to develop my interest in learning it happily, not feeling bored, no longer feeling so bad as before. I hope the teacher can provide some extra practical English materials, to master our sentence-making skills to better understand their structures, patterns and meanings. I hope we do not need to use all the original textbook materials; instead, the teacher can provide us with key words with focus on exam preparation, at the pace the class is conducted seriously, while sometimes sharing with life experience. I think English class is so interesting, that makes me feel like learning English better than before; hope the teacher can teach us more vocabulary to build up a more solid foundation, because I think the English language is very important as the most important international social and communication tool. I hope to improve myself, and am happy to have such a friendly and earnest teacher who explains more clearly, and makes student feel at ease in learning; that's great! The exam format is completely explained, and well-designed plus the teacher's nice, pleasant personality; I hope we could sing more English songs to improve English pronunciation and listening ability, My basic English literacy and knowledge needs developing and greatly improving because sometimes I do not understand what I am listening at all; neither do I know how to make sentences to express myself, so I hope the teacher could provide us with more useful basic books appropriate for the beginners, or show us if we would be able to borrow them from the library for extra reading or self-study.

The foreign language ability, especially English, is very crucial and influential in the modern age, we are lucky to have the very and beautiful teacher and perfect curriculum to enhance our basic reading and writing skills; she explains patiently and effectively the synonym, antonym and thesaurus of the key words to build our vocabulary skills, the grammatical structure and usage; I think it would encourage or increase the participation in class if the teacher could begin with the teaching of grammatical structure, patterns and vocabulary skills, then my interest in English would be highly raised and it would be more helpful for me to get a good job and do well at work; therefore, I have tried my best to improve my English abilities; however, although I realize the importance of the English ability in this information age, I don't feel what we are learning is practical and useful enough in the work place, so I am not feeling so interested in English course, and lack the motivation to study hard to enrich my life by working on English study; luckily we have the US-trained teacher who are teaching so seriously and earnestly, who had grown up and taught overseas; we have learned a lot from her cultural differences and habits and customs of foreigners; that's very practical and useful when we go global some day after we graduate. Moreover, we value the opportunity of interactions among the students in the classroom. It would be fine and great if such interaction and exchange should be increased.

"Students feeling it's not bad or fine with taking the English course, Say hurrah and cheers! Hope not to just copy or learn about the textbook content, suggest the course should increase the extra reading skill building by adding some content learning-related articles in English, enhance the listening skill training, because sometimes I feel out of hand knowing not how and where to begin when I face English, ...” So I do want to enhance English skills, as I don’t lack the motivation of an interest in learning it well, I know it is very important to first remember and memorize the vocabulary, but I forget what I had learned easily if I don't use it, and so I feel very frustrated and distressed. It is not so hard to learn the vocabulary, and it not so easy either; I think, as long as I study hard enough, I will learn well; glad to have a good teacher who has a sense of humor and makes the teaching very interesting. I hope to have more opportunities to communicate with foreigners, like the steady-paced progress of 
teaching, learn to master all the four skills, enhance the understanding the way good enough to study it without any pressure put on us, and that suits the needs of our study. We sometimes benefit much from the extra materials outside of the classroom materials, with the use of many sources to learn English, and the teaching style is quite impressive in getting a better understanding of the language as a whole, with the explanation of both the domestic and foreign cultures, which greatly raises students' interest, enhances interaction, raises four English skills,. This semester I had more private businesses to do, so I did not study very hard, and felt very disappointed at my performance, But I hope to improve before the end of the semester, based on all that I have learned about some terms, vocabulary, I will learn more vocabulary, from which I have learned a lot from the teacher about more foreign cultures, thus better understanding that English is the most important tools to work and travel in the future, if I can study harder to enhance and master the English skills ,Though I don’t like to memorize vocabulary or grammar, I still have to find some effective ways to be able to digest to overcome the obstacle. With the vocabulary I have learned, I need to pick up the English course that I misses for three years; it’s pity. However, after studying English over this year in this course, I feel my English ability has improved a lot, depending not only on the teacher, but also on self. In short, English is useful and not hard to master if you are willing to learn, and do your best to devote your time and energy to under the guidance of the teacher to keep moving on.

I hope the teacher can supplement some more extra content related to the English course textbook covering all suitable and useful aspects which are good. The teacher is very nice but actually I'm not interested in English, so I feel a little sorry for not working hard enough though the teacher is so good and speaks beautiful English, although the students are interested in English, but they need to take a better, more positive learning attitude. Since the midterm we have been taught in class, when some extra materials were introduced, the teacher has a sense of humor, to enhance the students' attention, to understand their interest and evoke their ideas, so we all feel that the teacher is very great and teaching every seriously. Thus, I will be more conscientiously in studying English and I hope my classmates should take the learning as seriously as the teacher. I don't know how to memorize vocabularies effectively, but having a very conscientious teacher, I feel thankful to you; I hope the teacher can use some more foreign movies or albums, to better help us get more familiar with the language, people, life and culture which are among the most important aspect of a language. I think of course content to be also very good, feeling we have learned textbook grammar well; we suggest you add more new and key words, grammatical structure to in the reading part of the textbooks or extra articles, to allow us to learn more to enhance our reading comprehension skill.

In order to put more interesting and useful contents into English learning content to back up and support the textbook, the teacher has added a lot of extra materials, which helps us a lot. She is very nice, earnest and patient in teaching us, and so, after the two semesters, I found my English has improved a lot. Whenever I didn't understand what the teacher said, I would ask my classmates next to me, and the teacher noticed and would give us enough time to review, digest and absorb. The teacher is so very careful and thoughtful and open-minded that she sometimes share a lot of travel and study experiences in the US, inspiring our interest in paying more attention to international and foreign affairs. In short, I think she is very serious and patient teacher, doing her best to let us feel at ease and enjoy studying by providing us many different kinds of English extra curriculum materials, to enable us to learn and absorb knowledge from a diverse source, hoping to help us improve our passion for English learning in the most effective and interesting possible way. The teaching is never boring; it's, very vivid, active and full of life with supplemented vocabulary and grammar materials, which make me pay more efforts in enhancing my English, Teacher, you are excellent! From time to time, her use of movies and scraps to let us learn many practical vocabularies, ready to utilize in our daily lives, Also, the teacher would share her life experiences in foreign countries to echo what's covered in the textbooks. To deepen our and increase our impression on the curriculum. We love to hear more interesting things, understand different cultures both east and west, using her first-hand interesting stories and things interesting about her experience living abroad. Her positive attitude toward life and teaching indeed encourage me to improve English, so as to visit many different countries in the future on my own. 
I feel I must study hard enough, to build my vocabulary skill and master grammar rules and structures in order to achieve my goal is to get passed in the GEPT test in the first place, I am determined to study I can no matter what replacement teacher continues to teach me I will keep working hard to follow her guidance to make the steady progress, by following and using all her effective ways of studying English, interactive ways in oral language, the TOEIC teaching content and testing strategies, in addition to the textbook, to practice to master all the diverse teaching materials as well as those secondary materials with timely and updated information added up, not just focusing on the textbook, but also relevant TOEIC-oriented materials. Lastly, I hope the textbook should contain more grammatical structures and reading, more movie-watching series.

Regarding studying English as a very important tool for international communications in being able to learn to use English to connect with the world, I feel the English course can be made more flexible, aimed at gaining or acquiring more knowledge, be more helpful in life or at work in the future, learn more to update my teaching methods, and increase my professional skills; therefore, I propose that the teacher should add more extra exam exercises to practice preparing for the targeted tests; this includes teaching more useful English vocabulary and grammar, should not gossip too much, teach more not just a bit of the useful English expression since English is one of the key essential abilities of modern life, whereas the teaching in the classroom may not be necessarily helpful and ready for immediate daily use, and students love being fun and lively talking, don't want to learn seriously, but mostly aim at getting a good job; therefore, we had better let students be more interested first in such themes as to attract them to actively and effectively participate and remember firmly. I therefore feel that English, though thought to be very difficult in the past, is now regarded by all as a need to be used in many places; for example , going abroad is also very practical reason for speaking fluent, clear and effective English, and so, I believe, in order to teach students to speak fluent English, it is really a bit difficult for them to absorb the essence of the language in class flat with no feelings, making learning English though very good, yet difficult to be able to put to use in everyday life. In addition to classroom learning, the first stage of self-study on basic grammar and vocabulary can be relatively easy, if they can be presented in the form of playing movies so as to first inspire students' interest in listening and watching English being spoken at the same time, while the progress may be slow in the beginning, the long-winded, requiring to take note, and learning more in the curriculum as a back-up, by not being just limited to the content of textbooks. This way, there would be a great help by offering far more opportunities offered for realistic learning, thus substantially improve their English proficiency. As for me, since a child I like to listen to English songs to enhance my listening ability as input and that is a big help for my output-producing what I have heard to speak relatively fluent and correct English.

Course thoughts: The teacher taught from the beginning in such a very careful and patient way that has transformed me as low achiever students absolutely not having any interest in English into a passionate language learner. I think that learning English must follow a gradual step-by-step processes; it starts by taking a little sense of accomplishment, which can spur or to stimulate the motivation of the learner to continue the follow-up efforts, to move up to a bit more difficult and challenging stage; however, if he or she does not use what has been learned often, mostly words or expressions remembered would fade away or disappear immediately, because when not in use, they are easily forgotten. I think there is a simple way to learn English, and that makes suddenly I feel English is not that difficult to learn, well, at least I have never thought myself to be have a correct pronunciation, and it is very easy to correct it; for example, often at exams, I heard this questionnaire came from a beautiful teacher, looking very nice with a beautiful voice, then we will study it passionately and efficiently, because the teacher taught us the most basic KK phonetic symbols and teach us a little bit of English learning concept, but because of not reviewing what's covered every day, I failed to learn to spell correctly; however, there is no way to pronounce right, although I'm not interested in English, but the future trend had needed us to have it right, to understand the range of students' abilities. No big feelings, because it is a compulsory or required course, even there is not much interest in English for me now, so my learning is not effective, although learning a language is life-long processes; I have no comment on this point. 


\section{Appendix E: A Survey of Need Analysis for Sophomore-Year Students in ESP English Study}

Please make suggestions to your teacher of your most favorite ways of planning your ESP course

...Focusing on basic GEPT or TOEIC tests (including Listening and reading sections), translating, understanding the meaning, following the way of teaching, learning from the teacher, watching movies, playing or screening more English films, with subtitle in English, teaching all the basics or essentials of language, practicing doing grammar exercises, teaching while speaking

Being more active and practical in practicing conversational English, like listening to the teacher's life stories and learn from them, teaching by identifying the main points, following the step-by-step procedure, being more active and proactive, and more communicative, explaining the grammatical structure or patterns by using those easily confused grammatical changes, practicing grammar exercise while reading, taking it easy with more dialogues, alright, in a more relaxing way of the teaching environment and doing a dialogue, watching the films thought to be a more interesting, and effective approach to teaching more slangs and idioms or colloquial expression, sharing more life experiences, stories in more interactive ways, watching English movies, listening to English songs, reciting their lyrics to give more listening and speaking training, followed and guided by the teacher's teaching methods; we hope the teacher can speak louder in a slower pace. It would be much better to be teaching how to build vocabulary power, and practicing taking more English tests

Learning by playing it, practicing starting or having more dialogues, using specific terminology, honing more reading and speaking skills, storytelling skill, creating an all-English environment classroom, becoming more interactive with students, introducing more outside reading texts or articles or textbooks, opening diversified courses, enhancing more listening and speaking skills, following the way the teacher chooses to as they see fit., practicing using more vocabularies, English news reading, including more of the serious, interactive materials, songs, films, and articles

Followed by her way, more active way of teaching, more outside-the-class activities, more interesting and fun time on watching select films, performances, more interaction among students and the teacher, more translating practice, utilizing technology to become accessible to learning and listening resources; I want to be in level-C, so as to be engaged in more English dialogues

No special ideas, following by the teacher, taking it easy

Using more interesting way, English film

No idea, suggest organizing some interesting activities sometimes, watching more movies which should be more interesting, of much better quality or content or story, getting more interactive and natural or active while practicing more English conversations, facilitate and improve communication, remaining the same, studying to hone more listening and speaking skills, discussing in groups, practicing integrated four skills including: listening, speaking, reading and writing, and finally adding more current events or new reports to study and increase the vocabulary.

\section{What are your least favorite ways of planning your ESP course?}

Cohesion. Do not skip, do not rush, just like the current class, don't like reciting, Homework has been compulsory, writing on the blackboard in class, has asked me to memorize words. Grammar, written with no idea, thinking of knowing everything, but seeming to be too complex

Scripted, examinations, complex content; conducting the whole English classroom, teaching by mainly using the textbook, the book-warm way of reading; death read, memorize , acting or performing, role-playing, ... has been done in accordance with the textbooks, too much school work and too many exams or quizzes, read the text, filling, law-abiding, PPT, forced back words with examinations, the examination-oriented teaching, to intimidate or threaten with the results by punishment, does not know where to focus on. 
Continue to have class, dull or boring, no fresh or concrete idea, teaching entirely according to the textbooks, static or still, no interaction, do not like too rigid a way of teaching, read articles, take examinations, do role-playing, just look at slides

Speak English the whole time, do not understand, but my teacher does not only teach the content following the textbook, the course synchronized with textbooks, do not jump or skip over, take examinations, too stiff in course presentation, forced to memorize the book, or read the text...

Cram, none, memorize

Follow by the textbook

Exams, too monotonous, memorize a bunch of words with the grammar tests, do reports, basically not boring is to be acceptable, capable of chatting with foreigners, no listening portion to be enhanced, no partner to discuss with each other to make their own efforts, to read only textbooks as the only reading source

\section{What is your expectation of this course?}

Good, achieving ideal GEPT test results before graduation or get a TOEIC score of 550 points; I hope to improve English to be very good; be able to learn a little more English vocabulary to improve our own strength, to be in a more lively animated class; I hope the teacher can stay in our class to keep on teaching us hoping to become more comfortable using English; to be able to read the dialogues aloud on my own, and learn a foreign language efficiently getting results.

No, I hope my English is getting better; hope to obtain the relevant job licenses before graduation, to enhance English ability, to practice English conversation; hope to learn more about English, gain more knowledge about its language and culture and values; can communicate with foreigners more boldly and naturally; bravely

learn something outside of the textbook with more focused' do not read just to get the answers, supplement study on words and phrases sentence grammar; and extra materials beyond the textbook knowledge; do free play, using English in daily life to become a natural and fluent English language speaker, learn the English language happily, learning to recognize or locating or identify multi-point-meaning word, successful completion of the course, can get passed in due course, counseling students on how to pass the GEPT

Hope to improve English skills, being able to speak fluent English, none, hope to enhance all the four skills of English listening, speaking, reading and writing; can learn more about the English knowledge and culture and their more diversified phenomenon; I hope to be able to attend a more lively and energetic or vigorous class, which is more interesting and inspiring in learn words, becoming more skilled and capable, learning more colloquial usage of English expression by native speakers abroad

English learning can be made progress, through ordinary, good, or diversified teaching, so as to enhance English proficiency level, with more words to increase the vocabulary bank or size thus building a large word power. I hope you can learn more about grammatical rules, structures and their usage and applications,

Can progress be made in accordance with the teacher's way of teaching, hoping that the English get better and better after attending the course?

None

No, you can learn more relevant things by using English by making persistent efforts; conducting more of these activities, doing dialogues fluently having the ability to communicate with foreigners; further, to be able to do more to explain things in listening, understanding and future development of relevant English textbooks, to ensure that such ESP courses are much more interesting, focus and practical or pragmatic, to learn all the useful dialogues, fully increasing the amount of words, and not being afraid to talk to foreigners in English, to increase their English level to connect to the world with better job and career chances for a brighter future. 